\title{
Sonniges Geburtstagskind
}

- Kaum kommt die Frühlingssonne zum Vorschein, erwachen die Lebensgeister. Der lange Winter hatte bei mir bereits phlegmatische Auswirkungen. Doch das ist jetzt zum Glück vorbei. Mein Balkon ist Zeuge. Vergangenes Wochenende habe ich auch ihm neues Leben eingehaucht. All diejenigen unter Ihnen, die stolze Gartenbesitzer sind, werden mich jetzt vielleicht belächeln. Aber meine Acht-Quadratmeter-Oase auf Vordermann zu bringen, war meine ganz persönliche Gartentherapie. Unkrautjäten, Rankpflanzen zurechtstutzen, Gartenmöbel zusammenschrauben ... herrlich.

- Längere Tage und wärmere Temperaturen sind mein Motor. Ich bin wieder voller Tatendrang und hab mich auch gleich für den Ergotherapie-Kongress in Bielefeld angemeldet. Dabei freue ich mich nicht nur auf spannende Themen und Vorträge, sondern auch auf inspirierende Gespräche ... vielleicht mit Ihnen? Denn: Ihre ganz persönlichen Geschichten aus Ihrem Berufsalltag, worauf Sie besonders stolz sind, was Sie erheitert, was Ihnen Sorgen macht und was Sie einfach mal loswerden möchten, ist der Stoff, aus dem ergopraxis gemacht ist.

_ Und damit bin ich auch schon bei unserem Geburtstagskind. ergopraxis wird diesen Monat fünf Jahre alt. Die Kerzen haben wir bereits ausgepustet - natürlich nicht ohne Wünsche: Für die nächsten fünf Jahre hätten wir gerne weiterhin so treue, inspirierende, kritische und neugierige Leser wie bisher!

Herzliche Grüße und vielleicht bis zum Ergotherapie-Kongress,

Ihre

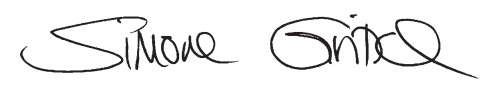

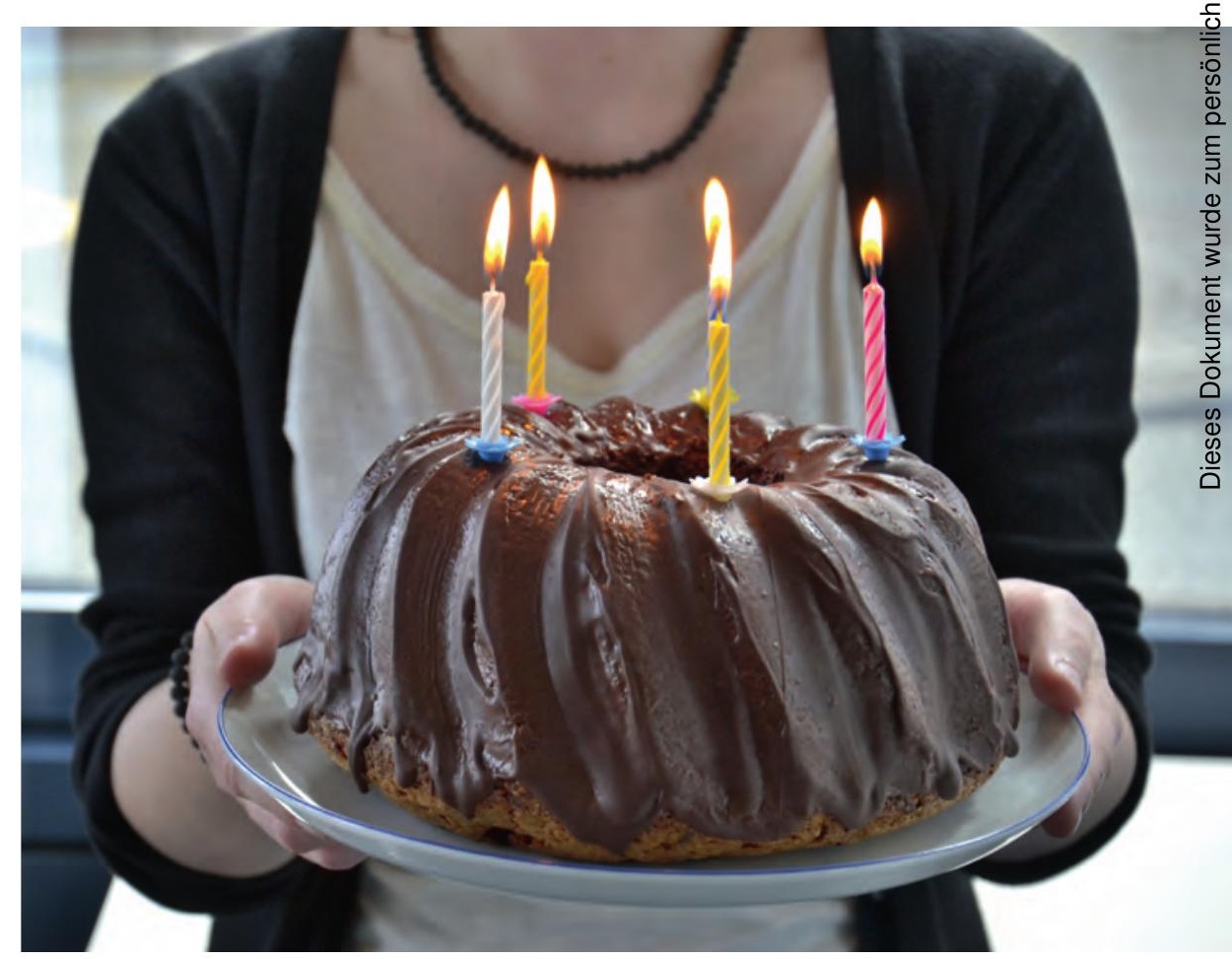

